\title{
Trombosis de la vena yugular interna secundaria a faringoamigdalitis aguda
}

\author{
Thrombosis of the internal jugular vein secondary to acute pharyngotonsillitis
}

\author{
Dra. Giselle Cuestas ${ }^{a}$, Dra. Yesica Lijdens ${ }^{a}$, Dra. María Victoria Demarchi ${ }^{a}$ Dra. María Pía Martínez Corvalán ${ }^{a}$ \\ Dr. Juan Razettia y Dr. Carlos Boccio
}

\begin{abstract}
RESUMEN
La faringoamigdalitis aguda es una de las enfermedades más comunes en niños y adolescentes. La etiología más frecuente es la viral, seguida por la bacteriana. Entre las causas bacterianas, el principal agente es el estreptococo beta hemolítico del grupo A. Una complicación infrecuente de los procesos infecciosos faríngeos es la tromboflebitis séptica de la vena yugular interna. El diagnóstico se sospecha ante la tumefacción laterocervical unilateral de carácter inflamatorio. Se confirma mediante tomografía computada con contraste. El tratamiento consiste en la administración prolongada de antibióticos; el uso de anticoagulantes es controvertido. El diagnóstico precoz y el tratamiento apropiado son esenciales para evitar la oclusión vascular persistente y la progresión del trombo, que puede ocasionar émbolos pulmonares.

Presentamos a una adolescente con tromboflebitis de la vena yugular interna secundaria a faringoamigdalitis aguda estreptocócica, con el objetivo de describir las manifestaciones clínicas, los métodos diagnósticos y el tratamiento de esta rara complicación vascular.

Palabras clave: trombosis de la vena yugular interna, faringitis aguda.
\end{abstract}

\begin{abstract}
Acute pharyngotonsillitis is one of the most common diseases in children and adolescents. The most frequent etiology is virus, followed by bacteria. The main bacterial agent is beta hemolytic Streptococcus group A.

A rare complication of pharyngeal infectious processes is septic thrombophlebitis of the internal jugular vein. The diagnosis is suspected in the presence of an inflammatory unilateral neck swelling. The diagnosis is confirmed by contrast computed tomography. Treatment consists of prolonged administration of antibiotics, being the use of anticoagulants controversial. Early diagnosis and appropriate treatment are essential to prevent persistent vascular occlusion and progression of the thrombus, which can cause pulmonary emboli.

Inthepresentstudy, wepresenta teenager with thrombophlebitis of the internal jugular vein secondary to acute streptococcal pharyngotonsillitis. Clinical manifestations, diagnostic methods and treatment of this rare vascular complication are described herein.
\end{abstract}

Keywords: thrombosis of the internal jugularvein, acute pharyngitis.

a. Servicio de Otorrinolaringología Infantil. Hospital Italiano de Buenos Aires.

\section{Correspondencia:}

Dra. Giselle Cuestas: giselle_cuestas@yahoo.com.ar

Conflicto de intereses: ninguno que declarar.

Recibido: 3-3-2014

Aceptado: 2-6-2014 http:/ /dx.doi.org/10.5546/aap.2014.e269

\section{INTRODUCCIÓN}

La faringoamigdalitis (FA) aguda es un proceso febril, generalmente de origen infeccioso, que presenta inflamación de las mucosas de la faringe y/o las amígdalas palatinas. ${ }^{1}$ La mayoría es de causa viral y autolimitada. ${ }^{2}$ Cuando la etiología es bacteriana y no se trata de forma adecuada, pueden ocurrir complicaciones, supurativas y no supurativas. La más frecuente es el absceso periamigdalino.

La trombosis de la vena yugular interna (VYI) es una complicación infrecuente que se debe considerar en el diagnóstico diferencial de tumefacción laterocervical de carácter inflamatorio relacionado con procesos infecciosos faríngeos y, más raramente, odontógenos. ${ }^{3,4}$

\section{CASO CLÍNICO}

Paciente de sexo femenino de 15 años de edad, con antecedente de FA a repetición; consulta al Servicio de Otorrinolaringología Infantil del Hospital Italiano de Buenos Aires por fiebre y odinofagia de 7 días de evolución sin mejoría con el tratamiento con penicilina iniciado hace 3 días, después de un test rápido estreptocócico positivo.

Al momento del examen físico, se evidencian amígdalas hipertróficas e hiperémicas con exudado purulento y se palpan adenopatías cervicales bilaterales. No presenta signos de protrusión periamigdalina, por lo que se descarta absceso periamigdalino. Se rota esquema antibiótico a amoxicilina-ácido clavulánico $(2 \mathrm{~g} /$ día).

A las 24 horas, consulta por empeoramiento del estado general y dolor profundo en la región cervical derecha, donde presenta tumefacción mal delimitada. Se acompaña de fiebre persistente, odinofagia intensa, disfagia y trismus.

Se decide su internación para administrar la medicación por vía parenteral y se realiza tomografía computada (TC) cervical con y sin contraste. Esta revela un defecto de relleno de $5 \mathrm{~mm}$ en la VYI derecha compatible con trombosis 
y linfoadenitis (Figuras 1 y 2 2). No se observan colecciones.

La radiografía de tórax es normal.

En el análisis de sangre, se destacan $9400 / \mathrm{mm}^{3}$ leucocitos (predominio de neutrófilos), proteína $C$ reactiva positiva $(28,1 \mathrm{mg} / \mathrm{L})$ y transaminasas levemente elevadas. Los estudios serológicos para virus de Epstein Barr y citomegalovirus son negativos.

Se realizan hemocultivos y cultivo de fauces para identificar gérmenes aerobios y anaerobios, y se inicia tratamiento empírico con ampicilinasulbactam por vía endovenosa ( $1 \mathrm{~g}$ cada 8 horas) $\mathrm{y}$ tratamiento anticoagulante con nadroparina por vía subcutánea ( $0,6 \mathrm{ml}$ cada 12 horas).
Los hemocultivos son negativos y el cultivo de fauces es positivo para Streptococcus beta hemolítico del grupo A (EBHA). No se aísla Fusobacterium necrophorum (FN).

La paciente evoluciona favorablemente, disminuyen la fiebre, la tumefacción y el dolor cervical. Al cuarto día, se otorga el alta hospitalaria con antibiótico oral (amoxicilinaácido clavulánico, $3 \mathrm{~g} /$ día) y anticoagulación con heparina de bajo peso molecular (nadroparina, $0,6 \mathrm{ml}$ cada 12 horas), y se cumplen 2 semanas de tratamiento combinado.

Al mes, se decide realizar amigdalectomía bilateral por el antecedente de infecciones faríngeas recurrentes.

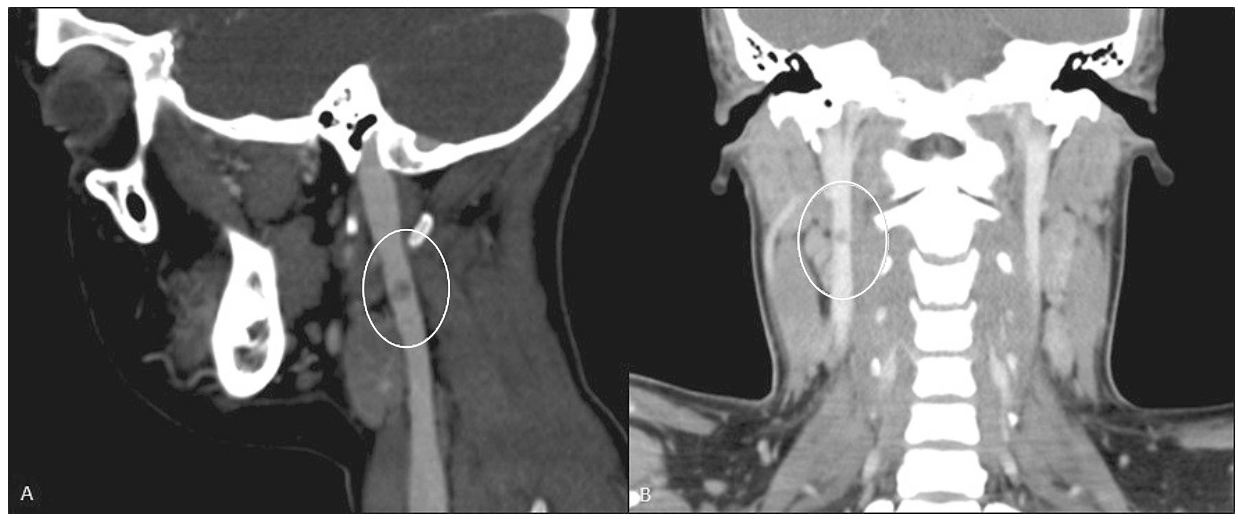

A. Corte sagital

B. Corte coronal.

FIGURA 2. Tomografía computada cervical, corte axial

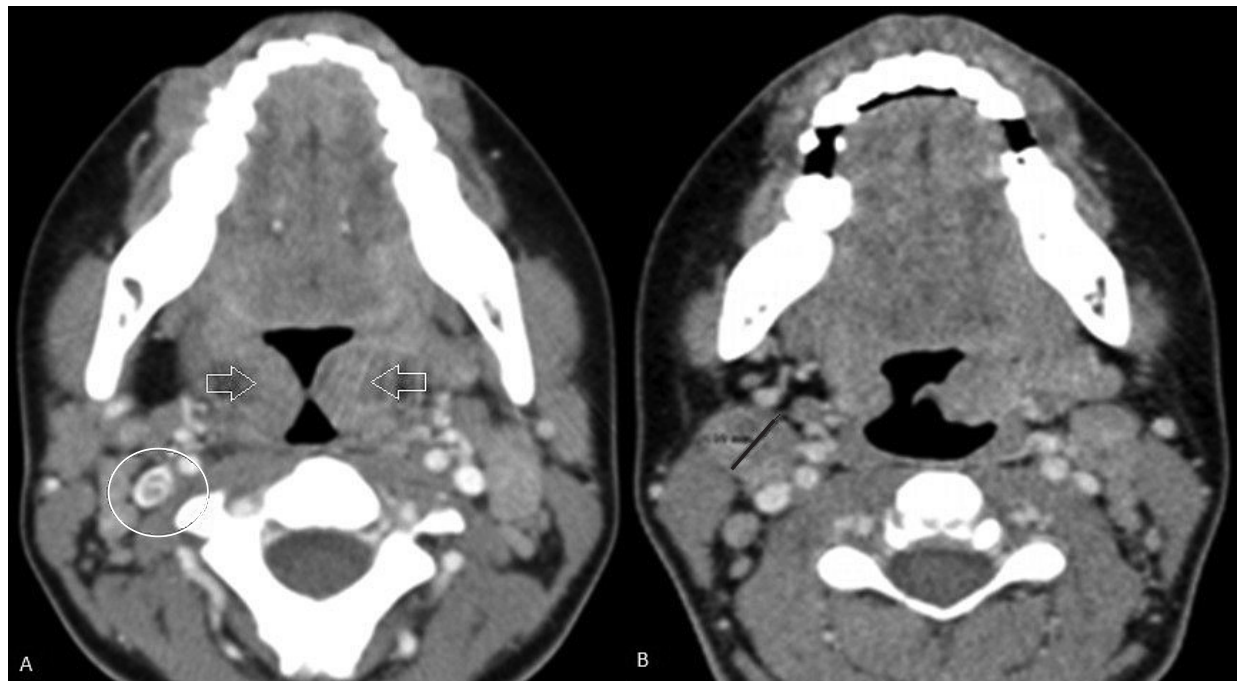

A. Se observa la hipertrofia amigdalina

B. Se observa adenopatía derecha (línea).

(flechas) y la trombosis de la vena yugular interna derecha (círculo). 


\section{DISCUSIÓN}

La tromboflebitis séptica de la VYI es una complicación poco común del espacio faríngeo lateral y faríngeo-maxilar. El origen de la infección del espacio laterofaríngeo puede ser por extensión directa, diseminación linfática, extensión perivascular o trombosis séptica de las venas amigdalinas. ${ }^{5}$ Esta patología se asocia a infecciones orofaríngeas y odontógenas, cateterizaciones venosas, adicciones parenterales y traumatismos. ${ }^{3}$ Cuando se asocia a una FA, el germen aislado con más frecuencia es el FN, bacilo gramnegativo anaerobio estricto implicado en el síndrome de Lemierre (FA, trombosis de la VYI, septicemia y embolismo pulmonar). ${ }^{3}$

La clínica habitual consiste en tumefacción de límite impreciso y dolorosa a la palpación, situada en la región submaxilar y a lo largo del borde anterior del músculo esternocleidomastoideo, con signos inflamatorios cutáneos. ${ }^{3,5}$ Evoluciona de forma lenta y progresiva. Puede acompañarse de fiebre, odinofagia, dolor y rigidez cervical.

El diagnóstico se confirma mediante la TC cervical con contraste, la cual tiene mayor sensibilidad que la ecografía para detectar la patología vascular, ya que es una imagen hipodensa en la luz de la vena indicativa de trombosis. ${ }^{3}$ Además, es muy útil en la definición de posibles complicaciones, como abscesos y celulitis perivasculares. ${ }^{5}$

La ecografía Doppler, si bien es un método rápido y exento de riesgos, no es capaz de detectar trombos recientes (por ser poco ecogénicos), cercanos al hueco supraclavicular o de poca longitud. ${ }^{3,5}$

El principal peligro de la trombosis de la VYI es la fragmentación o progresión del trombo, que puede ocasionar embolismo pulmonar. ${ }^{3}$ Otras complicaciones son la aparición de microabscesos por tromboflebitis supurativa y la oclusión vascular persistente (que se asocia con trombosis venosa recurrente e insuficiencia valvular venosa). ${ }^{3,6}$

El síndrome de Lemierre es infrecuente en la época actual pero grave, con una mortalidad entre el 4 y el 12\%. ${ }^{3}$ Siempre debe considerarse ante un cuadro de fiebre con antecedentes de infección orofaríngea, tumefacción laterocervical, signos de sepsis y, por lo menos, un sitio de infección metastásica (principalmente, en pulmón). ${ }^{7}$ Afecta con mayor frecuencia a adolescentes y adultos jóvenes sanos, entre los 16 y los 25 años. ${ }^{4,8}$ En ocasiones, se ha asociado a estados de inmunosupresión y drogadicción. ${ }^{5}$ La infección primaria es generalmente faríngea, pero se han documentado casos de infección odontógena, ótica y otomastoidea. ${ }^{6}$ El intervalo entre la infección primaria y la tromboflebitis de la VYI es de 1 a 3 semanas, por lo que, al momento del diagnóstico, la inflamación orofaríngea puede haberse resuelto o ser leve. ${ }^{8,9}$ En el $80 \%$ de los casos se asocia al FN. ${ }^{4}$ El diagnóstico es clínico, y las pruebas de imagen y los cultivos de sangre, fauces y colecciones confirman el cuadro. ${ }^{8} \mathrm{La}$ proteína $C$ reactiva invariablemente elevada y la leucocitosis neutrofílica son típicas. En un 50\%, la función hepática se altera. ${ }^{10}$

En nuestro caso, se descartó el síndrome de Lemierre por los hemocultivos negativos y la ausencia de embolias sépticas.

La FA recurrente y la falla de la penicilina para erradicar al EBHA pueden ser un problema clínico grave. ${ }^{11}$ Una de las explicaciones para el fracaso del tratamiento con la penicilina es que su administración repetida, como en nuestro paciente, da lugar a la selección de bacterias productoras de betalactamasa. ${ }^{11}$

No existe signo ni síntoma alguno que permita confirmar o excluir con certeza que la FA es de origen bacteriano o viral. Basándose en la alta especificidad, si el test de detección rápida del antígeno estreptocócico es positivo, se acepta que el paciente presenta una FA por EBHA, y no es precisa la confirmación mediante cultivo. ${ }^{1}$ En cambio, ante un resultado negativo, se sugiere realizar siempre cultivo. El cultivo de fauces es la prueba de referencia para el diagnóstico definitivo. Sus principales ventajas son la identificación y la determinación de la sensibilidad antimicrobiana de las bacterias causantes de la FA. ${ }^{1}$ En caso de FA de curso atípico, debe especificarse al microbiólogo la sospecha etiológica para utilizar además medios de cultivo específicos.

Además de los anaerobios, otros patógenos se han descrito como causantes de la trombosis de la VYI, entre los que se incluyen el EBHA y el Staphylococus aureus, así como flora mixta polimicrobiana. . $^{3,46}$

El FN no siempre se detecta en el cultivo debido a la terapia antibiótica previa o a su crecimiento más lento que el de los aerobios (puede tardar hasta 7 días en identificarse). ${ }^{10,12} \mathrm{El}$ diagnóstico molecular con la reacción en cadena de la polimerasa (PCR) es más caro que el cultivo, pero puede confirmar rápidamente la infección y ser útil en casos de cultivos negativos. ${ }^{2,7}$

El tratamiento de la trombosis de la VYI 
se basa en la administración de antibióticos y anticoagulantes. Es infrecuente la indicación de cirugía. ${ }^{3}$

El régimen antibiótico óptimo no se ha establecido. Se recomienda el uso empírico de antibiótico resistente a betalactamasas (fórmulas que contengan clavulánico o sulbactam) hasta obtener los resultados del antibiograma. ${ }^{9,13,14}$ Una alternativa es la monoterapia con clindamicina. Se administra por vía endovenosa hasta que desaparezcan la fiebre y el dolor cervical, y se continúa por vía oral hasta completar de 2 a 6 semanas de tratamiento. ${ }^{13,14}$

La anticoagulación es controvertida. Hay autores que contraindican su uso por el riesgo de diseminación de la infección. ${ }^{4}$ Los que están a favor sostienen que los anticoagulantes aceleran la recuperación, la resolución del trombo y previenen el tromboembolismo pulmonar.,

En ausencia de contraindicaciones, el tratamiento anticoagulante debe ser considerado en pacientes con escasa respuesta al tratamiento antibiótico inicial, con embolia séptica complicada o con predisposición a la trombofilia. ${ }^{4}$

La heparina de bajo peso molecular es el anticoagulante de elección en la población pediátrica. ${ }^{4}$ No parece existir consenso respecto a la duración del tratamiento anticoagulante; según autores, hasta de 3 meses. ${ }^{3}$ La heparina no está exenta de riesgos, efectos adversos e inconvenientes, especialmente en la población pediátrica, por lo que el control estricto por hematología es fundamental.

La ligadura o resección de la VYI es raramente necesaria; debe considerarse cuando el correcto tratamiento médico combinado (antibiótico y anticoagulante) no es efectivo en el control de los émbolos sépticos. ${ }^{15}$ En caso de abscesos, se indica el drenaje quirúrgico. ${ }^{15}$

Hay un incremento reciente de los casos documentados de trombosis de la VYI, con frecuencia complicada con embolismo pulmonar, posiblemente debido a la resistencia antibiótica y a cambios en el patrón de la prescripción de antibióticos. ${ }^{9}$

La demora en el diagnóstico debido a la falta de conocimiento de esta complicación es la principal causa de morbimortalidad. Queremos enfatizar la importancia de la sospecha clínica y del examen físico cuidadoso, con especial atención al cuello, para el diagnóstico temprano de esta entidad, que permita la instauración de un tratamiento eficaz.
Ante la falta de respuesta al tratamiento antibiótico, fiebre persistente, odinofagia y tumefacción cervical, se debe descartar mediante estudios contrastados el compromiso vascular $y$, si se acompaña de síntomas pulmonares, el síndrome de Lemierre.

\section{REFERENCIAS}

1. Piñeiro Pérez R, Hijano Bandera F, Alvez González F, Fernández Landaluce $\mathrm{A}$, et al. Documento de consenso sobre el diagnóstico y tratamiento de la faringoamigdalitis aguda. An Pediatr (Barc) 2011;75(5):342.e1-13.

2. BankS, Christensen K, Kristensen LH, Prag J. A cost-effectiveness analysis of identifying Fusobacterium necrophorum in throat swabs followed by antibiotic treatment to reduce the incidence of Lemierre's syndrome and peritonsillar abscesses. Eur J Clin Microbiol Infect Dis 2013;32(1):71-8.

3. Sanz Gonzalo JJ, Alobid I, Martínez Molina P, Arias Cuchi $\mathrm{G}$, et al. Trombosis de la vena yugular, a propósito de seis casos. Acta Otorrinolaringol Esp 2001;52(5):432-6.

4. Phan T, So TY. Use of anticoagulation therapy for jugular vein thrombus in pediatric patients with Lemierre's syndrome. Int J Clin Pharm 2012;34(6):818-21.

5. Laguía M, Lahoz T, Martínez J, Valero J, et al. Síndrome de Lemierre: tromboflebitis séptica de la yugular interna secundaria a amigdalitis aguda. Acta Otorrinolaringol Esp 2001;52(2):163-6.

6. Goldenberg NA, Knapp-Clevenger R, Hays T, Manco-Johnson MJ. Lemierre's and Lemierre's-like syndromes in children: survival and thromboembolic outcomes. Pediatrics 2005;116(4):e543-8.

7. Aliyu SH, Yong PF, Newport MJ, Zhang $\mathrm{H}$, et al. Molecular diagnosis of Fusobacterium necrophorum infection (Lemierre's syndrome). Eur J Clin Microbiol Infect Dis 2005;24(3):226-9.

8. Sánchez Acedo C, Martos Díaz PL, Muñoz Guerra MF, Naval Gías L, et al. Trombosis de la vena yugular interna y mediastinitis aguda necrosante descendente debido a una faringoamigdalitis aguda. Rev Esp Cir Oral Maxilofac 2010;32(3):119-22.

9. Kuppalli K, Livorsi D, Talati NJ, Osborn M. Lemierre's syndrome due to Fusobacterium necrophorum. Lancet Infect Dis 2012;12(10):808-15.

10. O'Dwyer DN, Ryan S, O'Keefe T, Lyons J, et al. Lemierre's syndrome. Ir J Med Sci 2011;180(2):565-7.

11. Brook I. Anaerobic infections in children. En: Curtis N, Finn A, Pollard AJ, eds. Hot topics in infection and immunity in children VII. New York: Springer; 2011.Págs.117-52.

12. Hagelskjær Kristensen L, Prag J. Lemierre's syndrome and other disseminated Fusobacterium necrophorum infections in Denmark: a prospective epidemiological and clinical survey. Eur J Clin Microbiol Infect Dis 2008;27(9):779-89.

13. Derber CJ, Troy SB. Head and neck emergencies: bacterial meningitis, encephalitis, brain abscess, upper airway obstruction and jugular septic thrombophlebitis. Med Clin N Am 2012;96(6):1107-26.

14. Li HY, Grubb M, Panda M, Jones R. A sore throat - potentially life-threatening? J Gen Intern Med 2009;24(7):872-5.

15. Dool H, Soetekouw R, van Zanten M, Grooters E. Lemierre's syndrome: three cases and a review. Eur Arch Otorhinolaryngol 2005;262(8):651-4. 